\title{
WOUND HEALING IN HUMANS BY OPTIMIZATION OF LOW FREQUENCY SIGNAL FOR PULSED ELECTROMAGNETIC FIELD THERAPY
}

\author{
Munna Khan (D), Shaila P.S.M.A. Sirdeshmukh (D) *
}

Electrical Engineering Department, Jamia Millia Islamia, New Delhi, India, 110025

Received - November 17, 2021; Revision - December 16, 2021; Accepted - December 20, 2021

Available Online - December 30, 2021

DOI: http://dx.doi.org/10.18006/2021.9(6).855.862

\section{KEYWORDS}

Pulsed Electromagnetic Field Therapy

Signal for Pulsed

Electromagnetic Field

Soft Tissue Healing

Wound Healing

\begin{abstract}
A wound, in clinical terms, is any tissue injury that causes skin rupture which penetrates epidermis and dermis layers leading to uncovering of underneath tissues or organs. Wounds can be superficial or deep, acute or chronic, with minor to serious implications depending on the source, extent, and location. Pulsed Electromagnetic Fields (PEMF) may have varying effects depending on the type of target tissue. Triggering a biological event requires a specific signal to be applied. The effectiveness of a PEMF device is mostly determined by the waveforms utilized in conjunction with the pulsing frequency. Choosing the right PEMF signal is a crucial step in developing a device that can address the challenges associated with chronic wound healing and speed up the healing process. Therefore, the optimization of the signal generator unit in the PEMF system for wound healing applications is a necessity before starting the further process. Hence, the present work of optimization of the PEMF system was carried out by selecting an optimal signal on the signal generator which produces a significant quantity of current in the particular tissue site to provide improved wound healing results. A total of 120 signal generator designs were simulated and optimized to six signal generators having frequencies of $10 \mathrm{~Hz}$, $20 \mathrm{~Hz}, 30 \mathrm{~Hz}, 40 \mathrm{~Hz}, 50 \mathrm{~Hz}$, and $100 \mathrm{~Hz}$ and duty cycle $25 \%$. For both groups, the average frequency and duty cycle were calculated and tested using independent samples t-test to see if there were any differences between them. No statistically significant difference was found for frequency $(\mathrm{p}=0.9977)$ and duty cycle $(\mathrm{p}=0.5090)$. Because of the necessity of the right PEMF signal selection for every trial to be successful, this work will act as a gateway for selecting, understanding, ' and considering the proper signal which could initiate the respective biological effect and accelerate the wound healing process.
\end{abstract}

* Corresponding author

E-mail: shailaparvin11@gmail.com (Shaila P.S.M.A. Sirdeshmukh)

Peer review under responsibility of Journal of Experimental Biology and Agricultural Sciences.

Production and Hosting by Horizon Publisher India [HPI] (http://www.horizonpublisherindia.in/).

All rights reserved.
All the articles published by Journal of Experimental Biology and Agricultural Sciences are licensed under a Creative Commons Attribution-NonCommercial 4.0 International License Based on a work at www.jebas.org.

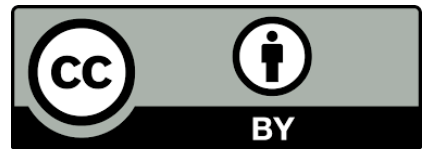




\section{Introduction}

Clinically, an injury or lesion is a complicated phenomenon that involves tissue injury that causes rupturing of the skin. The rupturing of the skin leads to penetration through epidermis and dermis layers which uncover the underneath tissues or organs. Wounds can be superficial or deep, acute or chronic, with minor to serious implications depending on the source, extent, and location (Schreml et al., 2010). Wound healing is a complex process in which damaged skin or other body tissue possesses the self-healing capacity but in the case of chronic wounds, it takes a rather long time without any instrumental aid (Janis \& Harrison, 2014; Borda et al., 2016). The cohesive wound healing process can vary greatly depending on the type of wound. The primary phases of wound healing are more or less similar in almost all situations which comprise blood clotting, inflammation, proliferation or growth of new tissue, epithelization, and maturation (George Broughton et al., 2006). The mentioned process can be accelerated using the help of many different technologies available currently (Kai et al., 2017; Amaroli et al., 2019; Costantini et al., 2019).

Electromagnetic field radiations released from different sources encircle us at all times. Wireless communication, mobile phones, power distribution networks, industrial machinery and electrical appliances, and computer screens, etc. are all examples of how they are firmly rooted in our way of life. ELF-EMF(Extremely Low Frequency Electromagnetic Field) is very frequently employed for diagnostic and therapeutic purposes like nerve stimulation, bone, and tissue repair by using a scanner, magnetic resonance imaging (MRI), and microwave imaging (Kheifets \& Shimkhada, 2005). Electromagnetic therapy is a simple and noninvasive way to treat injuries and offers a wide range of medical uses (Sutbeyaz et al., 2009).

Electromagnetic Field (EMF) is defined as a non-quantum field of force created with the flow of an electric charge. EMF comprises both electric and magnetic fields and is refers to a certain amount of electromagnetic (EM) energy. EMF refers to a certain amount of electromagnetic (EM) energy and comprises both electric and magnetic fields. ELF-PEMF (Extremely Low Frequency-Pulsed Electromagnetic Field) is a type of EMF that has frequencies ranging from $6 \mathrm{~Hz}$ to $500 \mathrm{~Hz}$ at the low side of the electromagnetic spectrum. EMF with a high value of frequency forms ionizing radiation while non-ionizing radiation is produced by EM fields with a low value of frequencies and quanta that are insufficient to break bonds between molecules.

PEMF is developed by passing a current through a loop or conductor, has shown promising outcomes for the treatment of osteoporosis, back pain, bone union, oncology, wound healing, nerve regeneration, etc. (Assiotis et al., 2012; Nelson et al., 2013; Kwan et al., 2015; Vadalà et al., 2016; Daish et al., 2018; Lisi et al., 2019). There are a wide range of methods for assessment of healing like bioelectrical impedance measurement, ultrasound, laser imaging, MRI (Khan et al., 2016; Jan et al., 2018; Elrefaie et al., 2020; Bretschneider et al., 2020). So far, researchers have discovered a wide range of outcomes following the use of PEMF stimulators to promote repair.

The application of magnetic and electromagnetic fields as therapeutic approaches began shortly after the Second World War with the invention and development of numerous electromagnetic signals (Markov, 2007a). It was discovered around this time that asymmetric or time-varying waveforms are more effective in comparison with symmetrical waveforms (Pilla, 2007). Different biological events can be triggered by a variety of waveform characteristics. Therefore, to trigger a specific biological event or process a particular specified signal should be applied. The diverse combinations of frequency, waveform, and amplitude in a PEMF device have varying impacts on living tissues. The effectiveness of a PEMF device is mostly determined by the waveforms utilized in conjunction with the pulsing frequency. PEMFs may have varying effects depending on the type of target tissue. PEMFs are defined as electromagnetic fields comprises of asymmetric or varying waveforms and have been shown to promote healing when used as add-on therapy (Pilla, 2007). The PEMF signals are inductively connected to target tissue location and hence referred as noninvasive (Bassett, 1989; Markov, 2004). The time-changing EMF allows for more current to be delivered to tissues as compared to a waveform with a slower rate of change and hence resulting in a better biological effect (Pilla, 2020). PEMF signals have a diverse set of spectrum components, allowing for potential connection to a wide range of biological signaling pathways (Shupak et al., 2003).

The problem of selecting the right signal for a particular application is most important and should be addressed first. To succeed in clinical trials, a decent knowledge of signals is a must requirement (Khan et al., 2017). Hence, the current work was carried out, mainly oriented on the optimization of a signal generator unit and accordingly simulation of PEMF based system was done that generates the optimal signal which may produce a considerable quantity of current in the injured tissue resulting in the improved wound healing process.

\section{Materials and Methods}

PEMFs are created when an electrical loop receives an electrical signal and generates an electromagnetic field. Each magnetic pulse generates a little electrical signal that helps cells heal themselves. The frequency of electromagnetic fields used in clinical treatment is usually less than $100 \mathrm{~Hz}$ and the magnetic flux density is between $0.1 \mathrm{mT}$ and $30 \mathrm{mT}$ (Markov, 2007b). The frequency of an electromagnetic field is one of the characteristics that define it. The 


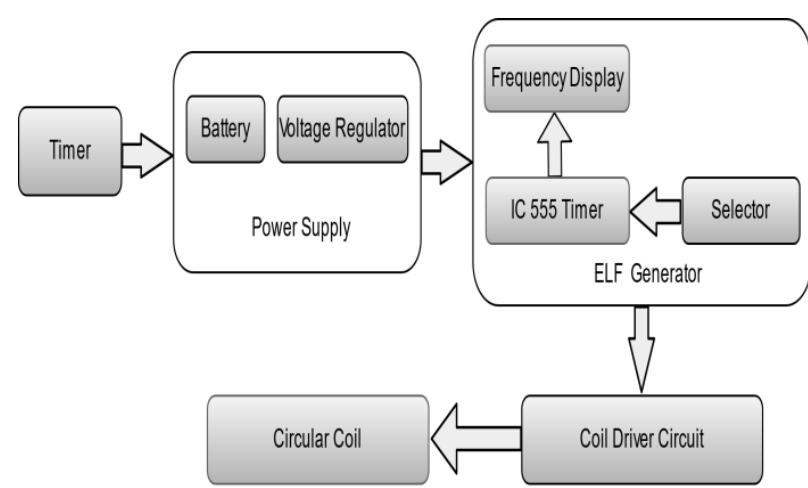

(a)

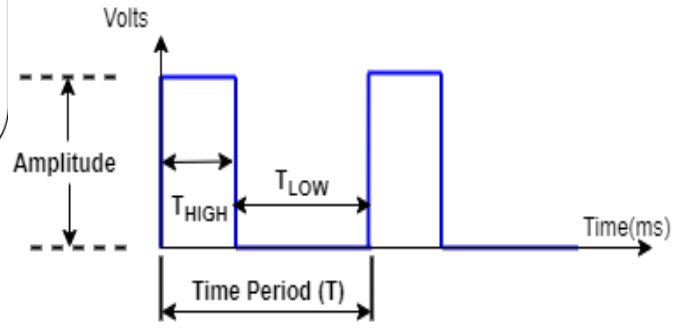

(b)

Figure 1 (a) Block diagram of ELF PEMF based System (b) Output waveform of IC555 defining the signal parameters.

primary goal of this research is to simulate an ELF-PEMF device that could generate pulsating waveforms in extremely lowfrequency ranges. It generates duty cycles of less than $50 \%$ with an optimal signal selection. The effectiveness of a PEMF device is also determined by the waveforms used and the frequencies at which they are used. A PEMF-based system depicted in Figure 1(a) includes a power source, an ELF waveform generator, a timer, a coil driver, and a magnetic coil that acts as an exposer. The power will go to the circuit by putting the timer in the "ON" condition which will generate the asymmetric waveform of duty cycle less than $50 \%$.

As a result, after the enhancement of the signal through the coil driver circuit, it will pass on to the circular coil. The electromagnetic field is created as a signal passes through the loop. With the help of the coil, the ELF PEMF field is administered to the targeted tissue. The ELF PEMF system is simulated through the simulation software NI Multisim. The electric circuit design is one of the most difficult areas and it necessitates the use of sophisticated tools to properly design circuits and check for flaws. NI multisim is an industry-standard Simulation Program with Integrated Circuit Emphasis (SPICE) simulation software. Many engineers and researchers utilize this SPICE program for simulating the analog, digital and other circuits to anticipate the performance of electronic circuits mathematically. This allows users to quickly examine and study the behavior of electronic circuits. Simulation of the circuit not only saves the time but the development cost too.

\subsection{Signal Generator Design}

Good signal quality, low cost, and ease of development are all advantages of our current design approach. This work was mainly oriented to signal generator unit with alteration in the values of passive components to increase the flexibility of the system. The signal generators using IC555 is in the current design generate rectangular waveforms with pre-calculated values of frequency and duty cycle. Whenever the knob of the rotary switch is rotated to select a particular frequency, the signal generator produces the value of frequency signal will get selected and all other generators will remain off. In a stable mode, the IC 555 switches between its two states at regular intervals, resulting in a rectangular waveform as depicted in Figure1(b). The external resistors (R1, R21, and $\mathrm{R} 22)$ are connected to discharge input via their junction. The fixed resistor, R21, and a potentiometer (R22) are connected in series, allowing the value of (R21 and R22) to be tuned for a specified duty cycle. To generate the rectangular waveform having a duty cycle less than 50\%, the value of (R21 and R22) is kept more than the $\mathrm{R} 1$. These resistors along with capacitor $\mathrm{C} 2$ had defined the time duration of the HIGH and LOW outputs by using equations $(4,5)$ in a stable mode and its frequency is defined by the expression (Schreml et al., 2010)

$$
f=\frac{1}{T}
$$

Where $\mathrm{T}$ is the time period of waveform which is the summation of the two distinct times that the capacitor charges and discharges can be expressed as:

$$
\mathrm{T}=\mathrm{T}_{\mathrm{HIGH}}+\mathrm{T}_{\mathrm{LOW}}
$$

So

$$
\begin{aligned}
& \mathrm{f}=\frac{1}{\mathrm{~T}_{\text {HIGH }}+\mathrm{T}_{\text {LOW }}} \\
& \mathrm{T}_{\text {HIGH }}=0.69 \mathrm{R}_{1} \mathrm{C}_{2} \\
& \mathrm{~T}_{\mathrm{LOW}}=0.69\left(\mathrm{R}_{21}+\mathrm{R}_{22}\right) \mathrm{C}_{2}
\end{aligned}
$$

The duty Cycle can be precisely tuned by changing the time constant of only one of the RC combinations.

$$
\text { Duty Cycle }=\frac{\mathrm{T}_{\mathrm{HIGH}}}{\mathrm{T}_{\mathrm{HIGH}}+\mathrm{T}_{\mathrm{LOW}}} \times 100(\%)
$$

The signal generators were designed for frequencies $10 \mathrm{~Hz}, 20 \mathrm{~Hz}$, $30 \mathrm{~Hz}$, and $40 \mathrm{~Hz}, 50 \mathrm{~Hz}$, and $100 \mathrm{~Hz}$ and the duty cycle was set to 
$25 \%$ by using the equations (Amaroli et al, 2019; Borda et al, 2016; Costantini et al, 2019; George et al, 2006; Janis et al, 2014; Schreml et al, 2010). A total of 120 signal generator circuits, twenty circuits for each frequency were designed by taking into account the various combinations of resistors and capacitors values.

\subsection{Waveform design consideration}

The effectiveness of a PEMF device is mostly determined by the waveforms utilized in conjunction with the pulsing frequency. Hence, waveform type, width or duration, output stimulation frequency, duty cycle are the pulse signal parameters that must be determined for a specific application. The system is designed to produce a rectangular waveform having a frequency $10 \mathrm{~Hz}$ to $100 \mathrm{~Hz}$ with a duty cycle of $25 \%$ for generating ELF PEMF. The time period, frequency, and duty cycle of the output waveform are determined by resistors and capacitor R1, R21, R22, and C2 components in the resistor-capacitor (RC) branches. Additionally, the Metal Oxide Semiconductor Field Effect Transistor (MOSFET) and passive components are included since they enable simple design and benchtop execution for pulse output testing. By altering the values of resistance and capacitance, it is feasible to generate the desired output signal with variable duration, frequency, duty cycle. Additional characteristics can be taken into account when it comes to the stimulation signal waveform. The waveforms of signals could be monophasic or biphasic. Biphasic signals could be balanced or unbalanced in charge and symmetric or asymmetric type in nature. In clinical trials using transcranial magnetic stimulation, monophasic signals have been demonstrated to be safe and effective (Kammer et al., 2001; Lazzaro et al., 2001). Asymmetric PEMF pulse having narrow width and high amplitude is very useful for better clinical therapeutic effect (Pienkowski et al., 1992). The current circuit generates the output signal of monophasic and asymmetric type in nature.

\subsection{Simulation of circuit}

The quality of the generated signal is important as it affects directly on the PEMF exposer quality. The simulation software NI multisim is a popular tool for design and simulation. The numerous parameters of the signal generator are analyzed with this simulation tool. The software is straightforward to use and allows you to quickly substitute resistors and capacitors of various values to get the desired signal. ELF PEMF system was simulated consisting of six signal generators which could generate a rectangular waveform of $10 \mathrm{~Hz}, 20 \mathrm{~Hz}, 30 \mathrm{~Hz}, 40 \mathrm{~Hz}, 50 \mathrm{~Hz}$, and $100 \mathrm{~Hz}$ with duty cycle $25 \%$. Using equations 1 to 6 , by changing the different combinations of resistors and capacitors, a total of 120 signal generator circuits were designed (20 for each frequency viz. $10 \mathrm{~Hz}, 20 \mathrm{~Hz}, 30 \mathrm{~Hz}, 40 \mathrm{~Hz}, 50 \mathrm{~Hz}$, and $100 \mathrm{~Hz}$ with duty cycle $25 \%$ ). After optimization of the PEMF signal for each frequency, the PEMF system for wound healing was simulated using the optimal values as depicted in Figure 2.

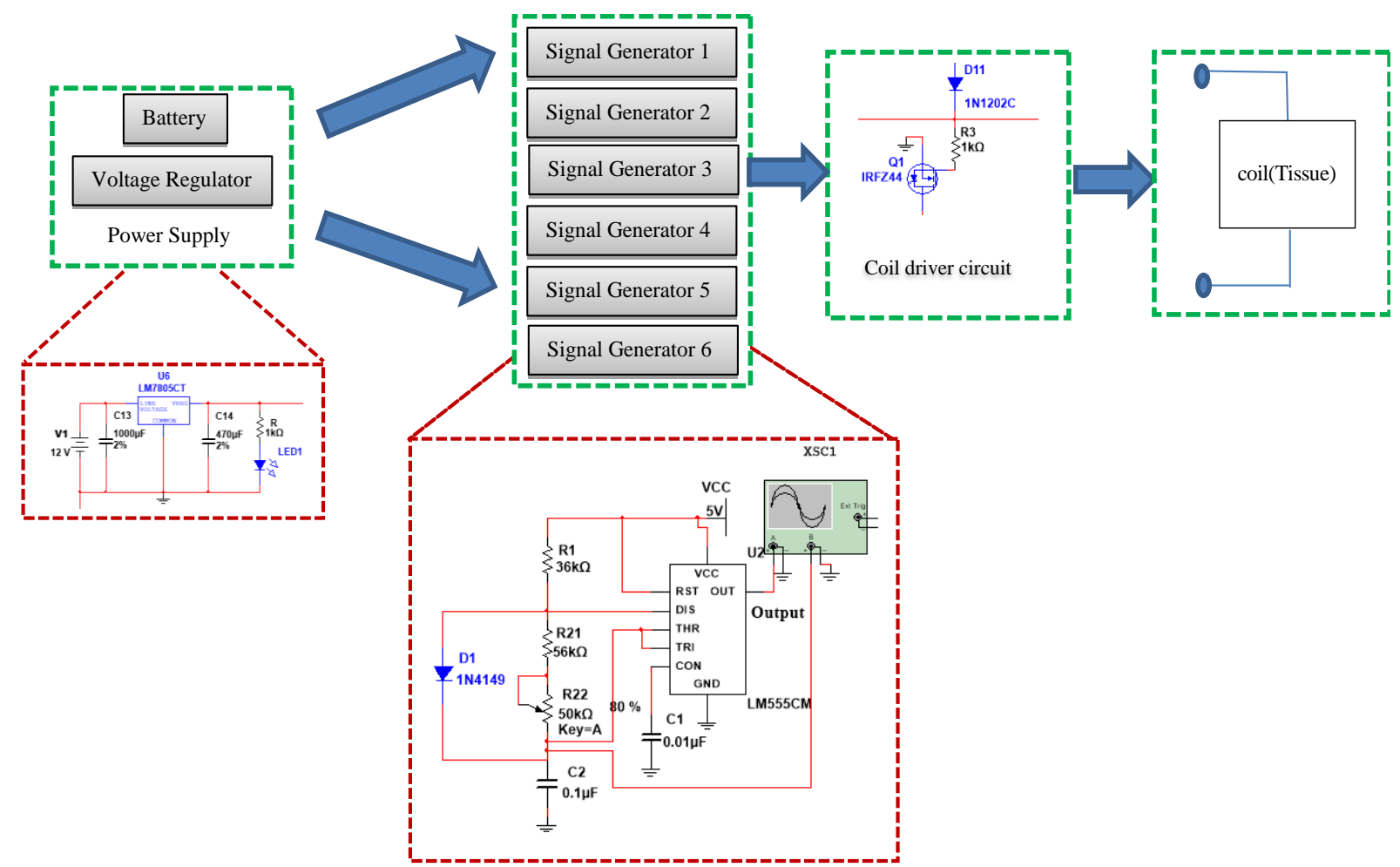

Figure 2 Simulation of PEMF based system using NI Multisim software

Journal of Experimental Biology and Agricultural Sciences http://www.jebas.org 
The power system includes a battery as a source and voltage regulator. The $12 \mathrm{v}$ battery was applied as a source of power supply. Most of the integrated circuits require a $5 \mathrm{~V}$ constant supply. Hence, there is a need of a voltage regulator to provide a consistent $5 \mathrm{~V}$ which is accomplished by addingLM7805 IC. A capacitor of 1000 microfarad (25v) was connected to remove any unwanted distortion in the $12 \mathrm{v}$ input. A filter capacitor was added at the output of the regulator to remove distortion if any in the regulated $5 \mathrm{v}$ supply. This $5 \mathrm{v}$ was utilized by IC555 timer for generating a rectangular waveform of desired frequencies and duty cycle. By using the rotary switch, a particular signal generator was selected which gave asymmetric waveform at the output. The coil driver circuit enhanced the asymmetric waveform using MOSFET and then finally passed to the magnetic coil for generating the Pulsed electromagnetic field. By placing the magnetic coil to the target site of the wound, the PEMF exposer is given for accelerating the healing process of a wound.

\subsection{Statistical Analysis}

To compare the difference between the simulated values and optimized value for frequency and duty cycle, an independent samples t-test were conducted using SPSS software. The significance level was set at $\mathrm{P} \leq 0.05$ for all the outcomes.

\section{Results and Discussion}

For every single frequency, twenty waveform generators using IC555 were designed to obtain a single optimal value. The criteria for optimization of the signal were the values of frequency in extremely low frequency PEMF signal viz. $\leq 100 \mathrm{~Hz}$ and duty cycle $\leq 25 \%$ (Markov, 2007b; Akbarnejad et al., 2017; Průcha et al., 2019). It means the pulse is rectangular in shape having less $\mathrm{T}_{\text {HIGH }}$ time than $\mathrm{T}_{\text {LOw, }}$ the signal will remain $\mathrm{ON}$ for short time and OFF for long period hence creating a non-thermal effect in tissue for promoting the healing process. Endothelial cells showed significant alterations in proliferation after the application of the LF EMF under conditions of a rectangular pulse mode (Varani et al., 2021). It is shown that the asymmetric PEMF pulse having narrow width and high amplitude is very useful for better clinical therapeutic effect (Kammer et al., 2001). Optimal selection of signal generator unit for generating optimized PEMF signal was carried out by plotting the graph between the frequency and duty cycle as depicted in Graph 1 for each frequency signal. It can be seen in Graph 1(a) out of twenty designs, the duty cycle and the frequency value of the signal for the first design is close to $25 \%$ and $10 \mathrm{~Hz}$ and hence falls under the selection criteria. Hence optimized design for $10 \mathrm{~Hz}$ frequency signal is the first design having optimal frequency value $10.16 \mathrm{~Hz}$ and duty cycle $25.35 \%$.

Similarly, the PEMF signals for all other frequencies were optimized and are given in the tabulated form in Table 1 .

The signal generator unit in the PEMF system generates the required waveform and can be used successfully in practical applications. The PEMF system for wound healing was then simulated to analyze the optimized values in NI Multisim Simulation software. Signal generators were simulated using the values of optimized design from Table 1. The output of each signal generator was observed using an oscilloscope in Multisim software as shown in Figure 3. It reveals that the output pulse is rectangular and has a shorter $\mathrm{T}_{\mathrm{HIGH}}$ time than $\mathrm{T}_{\mathrm{LOw}}$, indicating that it is asymmetric in shape.

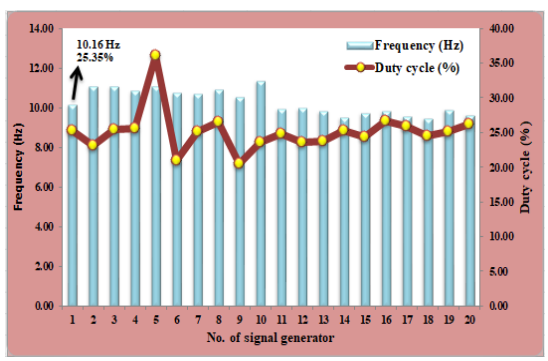

(a)

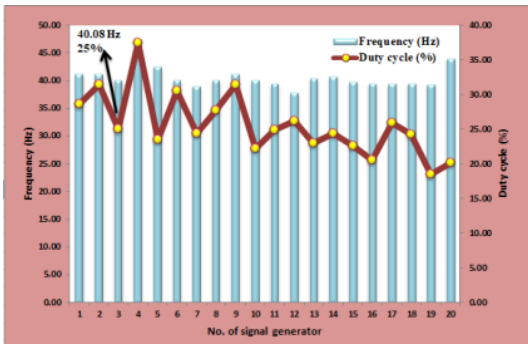

(d)

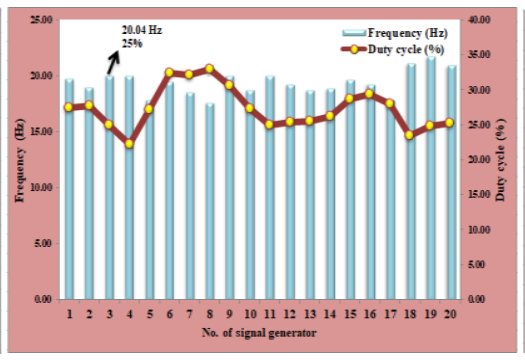

(b)

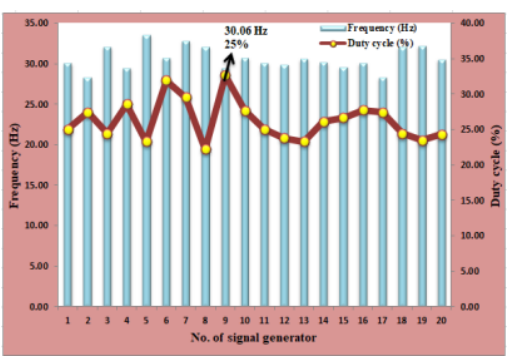

(c)

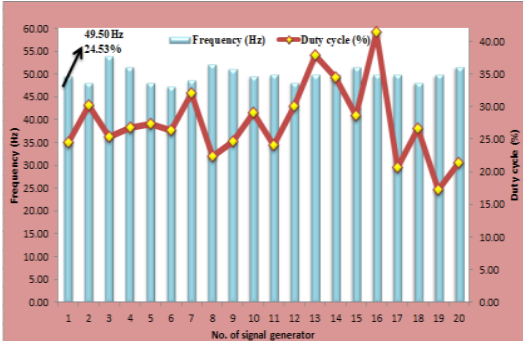

(e)

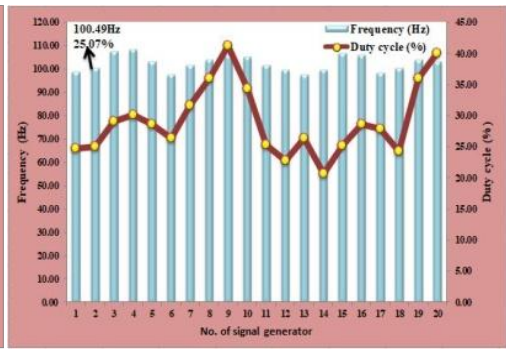

(f)

Graph 1 Optimization of signal generator in terms of frequency and duty cycle values having frequency (a) $10 \mathrm{~Hz}$ (b) $20 \mathrm{~Hz}$ (c) $30 \mathrm{~Hz}$ (d) $40 \mathrm{~Hz}(\mathrm{e}) 50 \mathrm{~Hz}$ (f) $100 \mathrm{~Hz}$.

Journal of Experimental Biology and Agricultural Sciences http://www.jebas.org 
Table 1: Comparison of Optimized value and simulated values of Output Rectangular Signal

\begin{tabular}{|ccccccc|}
\hline \multirow{2}{*}{$\begin{array}{c}\text { Total number of } \\
\text { signal generator }\end{array}$} & \multicolumn{3}{c}{ Optimized value } & \multicolumn{3}{c|}{ Simulation output value } \\
\cline { 2 - 7 } & Time (msec) & Duty cycle (\%) & Frequency $(\mathrm{Hz})$ & Time (msec) & Duty cycle (\%) & Frequency $(\mathrm{Hz})$ \\
\hline 1.00 & 98.41 & 25.35 & 10.16 & 99.43 & 25.40 & 10.03 \\
\hline 2.00 & 49.90 & 25.00 & 20.04 & 48.70 & 24.90 & 20.53 \\
\hline 3.00 & 33.26 & 25.00 & 30.06 & 33.14 & 24.92 & 30.17 \\
\hline 4.00 & 24.95 & 25.00 & 40.08 & 24.81 & 25.10 & 40.30 \\
\hline 5.00 & 20.20 & 24.53 & 49.50 & 20.07 & 24.97 & 49.80 \\
\hline 6.00 & 9.95 & 25.07 & 100.49 & 10.03 & 25.21 & 99.70 \\
\hline Average & & 24.99 & 41.72 & & 25.08 & 41.76 \\
\hline
\end{tabular}

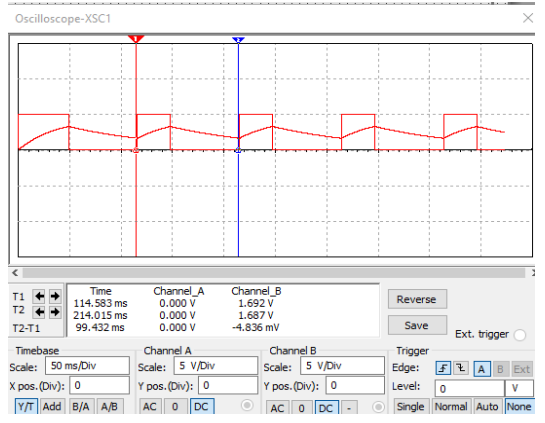

(a)

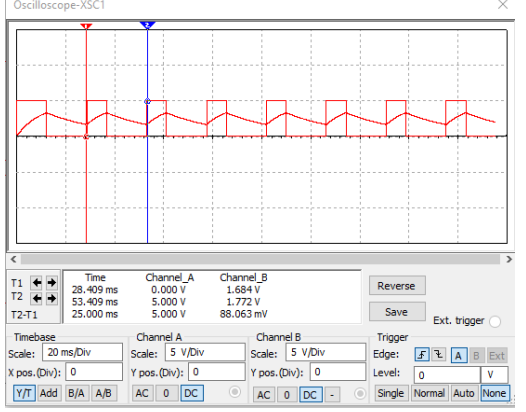

(d)

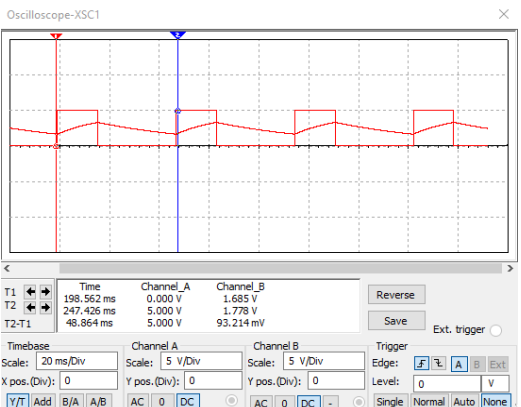

(b)

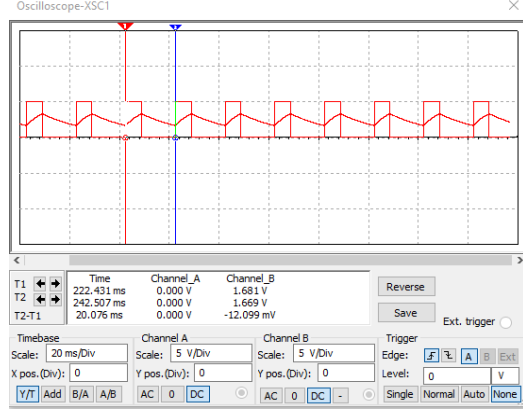

(e)

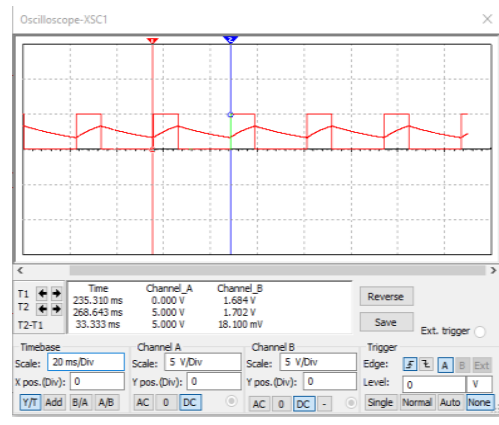

(c)

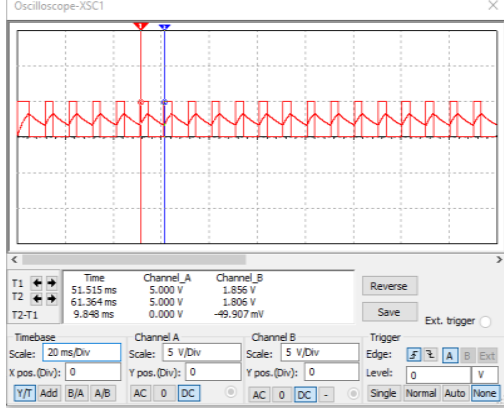

(f)

Figure 3 Simulated output of six signal generator is rectangular waveform having frequency (a) $10 \mathrm{~Hz}$ (b) $20 \mathrm{~Hz}$ (c) $30 \mathrm{~Hz}$ (d) $40 \mathrm{~Hz}$ (e) $50 \mathrm{~Hz}$ (f) $100 \mathrm{~Hz}$.

For both the groups the average of frequency and duty cycle values were calculated and tested using independent samples t-test to see if there were any differences between them. No statistically significant difference was found between the two observed groups for frequency $(\mathrm{p}=0.9977)$ and duty cycle $(\mathrm{p}=0.5090)$. Hence both simulated, as well as optimized values of a signal parameter, were in enclosed proximity. The findings of the current study showed that the optimized signal generator is capable to generate the asymmetric pulse having a duty cycle of $25 \%$ of the above discussed six frequencies. Due to the paucity of research works related to the optimization of PEMF signal the precise comparisons with other studies could not be pursued, which could be attempted in further studies.

\section{Conclusion}

Depending on the existing positive outcomes of the recently published literatures PEMFs have a lot of potentials to become a stand-alone or adjuvant treatment method for wound healing because of its non-invasiveness, safety, and efficacy, and no side effects. Wound healing has been viewed as a challenging issue to be examined due to its heterogeneity, diverse features and intricacy in the wound healing process, and a wide range of patient characteristics. Choosing the right PEMF signal is a crucial step in developing a device that can address the challenges associated with chronic wound healing and speed up the healing process. Ambiguity exists on the ideal mode of electromagnetic therapy, 
including trigger parameters, how stimuli are applied to the targeted region, magnetic field intensity, intake number, and duration of exposer length, among other factors. Because of the necessity of the right signal selection for every trial to be successful, the optimization of PEMF signal will act as a gateway for selecting, understanding, and considering the proper signal which could initiate the respective biological effect and accelerate the wound healing process. This study will act as a step towards the optimization of the physical window including signal frequency, waveform type duty cycle, and intensity. The results demonstrated in this study may be used for the development of a novel PEMF based system for accelerating wound healing. Therefore a novel concept of optimization of PEMF signal along with the optimized biological window would aid in producing consistent positive consequences.

\section{Authors' Contributions}

Study concept and design: S.P.S.M.A.S and M.K; Acquisition of data: S.P.S.M.A.S; Analysis and interpretation of data: S.P.S.M.A.S; Drafting of the manuscript: S.P.S.M.A.S; Critical revision of the manuscript for important intellectual content: S.P.S.M.A.S; Statistical analysis: S.P.S.M.A.S; Administrative, technical, and material support: S.P.S.M.A.S; Study supervision: M.K

\section{Conflict of Interest}

The authors declare that they have no conflict of interest.

\section{Funding Source}

No funding has been provided by the institution and the authors are responsible for their financial support.

\section{References}

Akbarnejad Z, Eskandary H, Dini L, Vergallo C, NematollahiMahani SN, Farsinejad A, Abadi MF, Ahmadi M (2017) Cytotoxicity of temozolomide on human glioblastoma cells is enhanced by the concomitant exposure to an extremely lowfrequency electromagnetic field $(100 \mathrm{~Hz}, 100 \mathrm{G})$. Biomedicine \& Pharmacotherapy 92:254-64.

Amaroli A, Ravera S, Baldini F, Benedicenti S, Panfoli I, Vergani L (2019) Photobiomodulation with 808-nm diode laser light promotes wound healing of human endothelial cells through increased reactive oxygen species production stimulating mitochondrial oxidative phosphorylation. Lasers in Medical Science 34(3):495-504.

Assiotis A, Sachinis NP, Chalidis BE (2012) Pulsed electromagnetic fields for the treatment of tibial delayed unions and nonunions. A prospective clinical study and review of the literature. Journal of Orthopaedic Surgery and Research 7(1):1-6

Bassett CA (1989) Fundamental and practical aspects of therapeutic uses of pulsed electromagnetic fields (PEMFs). Critical Reviews in Biomedical Engineering 17(5):451-529.

Borda LJ, Macquhae FE, Kirsner RS (2016) Wound dressings: a comprehensive review. Current Dermatology Reports 5(4):287-97.

Bretschneider H, Trattnig S, Landgraeber S, Hartmann A, Günther KP, Dienst M, Schröder J, Fickert S (2020) Arthroscopic matrixassociated, injectable autologous chondrocyte transplantation of the hip: significant improvement in patient-related outcome and good transplant quality in MRI assessment. Knee Surgery, Sports Traumatology, Arthroscopy 28(4): 1317-1324.

Costantini E, Sinjari B, D’Angelo C, Murmura G, Reale M, Caputi S (2019) Human gingival fibroblasts exposed to extremely lowfrequency electromagnetic fields: in vitro model of wound-healing improvement. International Journal of Molecular Sciences 20(9):2108.

Daish C, Blanchard R, Fox K, Pivonka P, Pirogova E (2018) The application of pulsed electromagnetic fields (PEMFs) for bone fracture repair: past and perspective findings. Annals of Biomedical Engineering 46(4):525-42.

Elrefaie AM, Salem RM, Faheem MH(2020) High-resolution ultrasound for keloids and hypertrophic scar assessment. Lasers in Medical Science 35(2):379-85.

George Broughton II, Janis JE, Attinger CE (2006) The basic science of wound healing. Plastic and Reconstructive Surgery. $1 ; 117(7 \mathrm{~S}): 12 \mathrm{~S}-34 \mathrm{~S}$.

Jan SN, Khan FA, Bashir MM, Nasir M, Ansari HH, Shami HB, Nazir U, Hanif A, Sohail M (2018) Comparison of Laser Doppler Imaging (LDI) and clinical assessment in differentiating between superficial and deep partial thickness burn wounds. Burns 44(2):405-13.

Janis JE, Harrison B (2014 ) Wound healing: part I. Basic science. Plastic and Reconstructive Surgery 133(2):199e-207e.

Kai H, Yamauchi T, Ogawa Y, Tsubota A, Magome T, Miyake T, Yamasaki K, Nishizawa M (2017) Accelerated wound healing on skin by electrical stimulation with a bioelectric plaster. Advanced Healthcare Materials 6(22):1700465.

Kammer T, Beck S, Thielscher A, Laubis-Herrmann U, Topka H (2001) Motor thresholds in humans: a transcranial magnetic stimulation study comparing different pulse waveforms, current 
directions and stimulator types. Clinical Neurophysiology. 112(2):250-8.

Khan M, Sirdeshmukh SP, Javed K(2016) Evaluation of bone fracture in animal model using bio-electrical impedance analysis. Perspectives in Science 8:567-9.

Khan M, Sirdeshmukh SP, Reza MQ (2017) Optimal selection of PEMF signal for wound healing system. In International Conference on Multimedia, Signal Processing and Communication Technologies (IMPACT) 24 November, 2017 (pp. 185-188). IEEE.

Kheifets L, Shimkhada R (2005) Childhood leukemia and EMF: review of the epidemiologic evidence. Bioelectromagnetics 26(S7):S51-9.

Kwan RL, Wong WC, Yip SL, Chan KL, Zheng YP, Cheing GL (2015) Pulsed electromagnetic field therapy promotes healing and microcirculation of chronic diabetic foot ulcers: a pilot study. Advances in Skin \& Wound care 28(5):212-9.

Lazzaro V, Oliviero A, Mazzone P, Insola A, Pilato F, Saturno E, Accurso A, Tonali P, Rothwell JC (2001) Comparison of descending volleys evoked by monophasic and biphasic magnetic stimulation of the motor cortex in conscious humans. Experimental Brain Research 141(1):121-7.

Lisi AJ, Scheinowitz M, Saporito R, Onorato A(2019) A pulsed electromagnetic field therapy device for non-specific low back pain: a pilot randomized controlled trial. Pain and Therapy 8(1):133-40.

Markov MS (2004) Magnetic and electromagnetic field therapy: basic principles of application for pain relief. In: Paul JR, Markov MS(Eds.) Bioelectromagnetic medicine, Taylor \& Francis, New york, U.S.A.

Markov MS (2007a) Pulsed electromagnetic field therapy history, state of the art and future. The Environmentalist 27(4):465-75.

Markov MS (2007b) Expanding use of pulsed electromagnetic field therapies. In: Markov MS (Ed.) Electromagnetic biology and medicine. Taylor \& Francis, New york, U.S.A.

Nelson FR, Zvirbulis R, Pilla AA (2013) Non-invasive electromagnetic field therapy produces rapid and substantial pain reduction in early knee osteoarthritis: a randomized double-blind pilot study. Rheumatology International 33(8):2169-73.

Pienkowski D, Pollack SR, Brighton CT, Griffith NJ (1992) Comparison of asymmetrical and symmetrical pulse waveforms in electromagnetic stimulation. Journal of Orthopaedic Research 10(2):247-55.

Pilla AA (2007) Mechanisms and therapeutic applications of timevarying and static magnetic fields. In: Frank SB, Ben G (Eds) Biological and medical aspects of electromagnetic fields, Taylor \& Francis, New york, U.S.A.

Pilla AA (2020) Pulsed electromagnetic fields: from signaling to healing. In: Markov MS, James TR, Erik IW (Eds.) Pulsed Electromagnetic Fields for Clinical Applications, Taylor \& Francis, New york, U.S.A.

Průcha J, Skopalík J, Socha V, Hanáková L, Knopfová L, Hána K(2019) Two types of high inductive electromagnetic stimulation and their different effects on endothelial cells. Physiological Research 68(4): 611-622.

Schreml S, Szeimies RM, Prantl L, Karrer S, Landthaler M, Babilas P (2010) Oxygen in acute and chronic wound healing. British Journal of Dermatology 163(2):257-68.

Shupak NM, Prato FS, Thomas AW (2003) Therapeutic uses of pulsed magnetic-field exposure: a review. URSI Radio Science Bulletin 307:9-32.

Sutbeyaz ST, Sezer N, Koseoglu F, Kibar S (2009) Low-frequency pulsed electromagnetic field therapy in fibromyalgia: a randomized, double-blind, sham-controlled clinical study. The Clinical Journal of Pain 25(8):722-8

Vadalà M, Morales-Medina JC, Vallelunga A, Palmieri B, Laurino C, Iannitti T (2016) Mechanisms and therapeutic effectiveness of pulsed electromagnetic field therapy in oncology. Cancer Medicine 5(11):3128-3139.

Varani K, Vincenzi F, Pasquini S, Blo I, Salati S, Cadossi M, De Mattei M (2021) Pulsed electromagnetic field stimulation in osteogenesis and chondrogenesis: signaling pathways and therapeutic implications. International Journal of Molecular Sciences 22(2):809. 